\title{
Role of Probiotics Against Mycotoxins and Their Deleterious Effects
}

\author{
Gabriel Vinderola $^{1} \&$ Alberto Ritieni ${ }^{2}$ \\ ${ }^{1}$ Instituto de Lactología Industrial (INLAIN, UNL-CONICET), Facultad de Ingeniería Química, Universidad \\ Nacional del Litoral,Santa Fe, Argentina \\ ${ }^{2}$ Laboratorio di Controllo Qualità e Sicurezza di Alimenti e Nutraceutici, Dipartimento di Farmacia, Università \\ degli Studi di Napoli Federico II, Naples, Italy \\ Correspondence: Gabriel Vinderola, Instituto de Lactología Industrial (INLAIN, UNL-CONICET), Facultad de \\ Ingeniería Química, Universidad Nacional del Litoral, Santiago del Estero 2829, Santa Fe (S3000FKV), \\ Argentina. Tel: 54-342-453-0302. E-mail: gvinde@fiq.unl.edu.ar
}

Received: July 10, 2014 Accepted: October 5, 2014 Online Published: October 7, 2014

doi:10.5539/jfr.v4n1p10 URL: http://dx.doi.org/10.5539/jfr.v4n1p10

\begin{abstract}
Probiotics are live microorganisms which when administered in adequate amounts confer a health benefit on the host. They commonly belong to the genera Bifidobacterium and Lactobacillus. Fermented milks haven been used as the main vehicle, so far, for their delivery to consumers. Mycotoxins are secondary toxic fungal products with a long history of responsibility for foodborne disease outbreaks. Human and animals are continuously exposed to variable levels of these contaminants (aflatoxins, ochratoxin A, fumonisins, deoxynivalenol, patulin, zearalenone, among others) that occur naturally in the diet. The long term exposure might cause tissue and genetic damage. Certain probiotic strains can bind and remove mycotoxins from liquid media. Eukaryotic cell cultures showed that the complex probiotic-mycotoxin is less adhesive to enterocytes than the probiotic alone, then favouring maybe the elimination of this complex from the gut through feces. Probiotics were also shown capable of restoring some functions of the epithelial cells after the damage produced by mycotoxin exposure. Animal trials revealed that genetic damage and tissue oxidation might be also partially avoided by the oral administration of probiotics. Finally, human clinical trials conducted in people naturally exposed to mycotoxins in food that received probiotics, showed reduced levels of mycotoxin-DNA adducts in urine and in the content of mycotoxins in feces. However, it remains to know the fate of the ingested mycotoxins that were not found in feces. In vitro to in vivo evidence is gathering in order to determine the role of probiotics on the prevention or partial remediation of the damage induced by mycotoxins.
\end{abstract}

Keywords: probiotics, Lactobacillus, mycotoxins, aflatoxins, binding, removal, intestine

\section{Introduction}

Our gut is the home of the so-called intestinal microbiota which is thought to account for $95 \%$ of the total cells in the human body and to sum up approximately $10^{11}-10^{12} \mathrm{CFU} / \mathrm{g}$ of intestinal content in the large intestine. We host more bacteria in the gut that people living all over the world. In order to support its constant elimination through feces, a lot of metabolic activity is carried out by the intestinal microbiota. Where do these bacteria come from? How do we get fully colonized very soon after birth and for our whole life? The intestine of the newborn is sterile at birth, but it gets heavily colonized in few days followed birth. The composition of the intestinal microbiota is relatively simple in infants but becomes more and more complex in adults. The sources from where the intestinal microbiota is derived are the own mother (vagina, skin, and breast milk) and the environment that the baby meets after birth and in which he is raised in the first years. There is a high degree of variability among human subjects on the genera, species and strains that colonizes them. This variability depends on dietary habits, geographical location, age, immune status, stress factors, and other factors not yet completely known (Sekirov, Russell, Antunes, \& Finlay, 2010). Due to the development of metagenomics, the intestinal microbiota has been more and more investigated lately (Martin, Miquel, Langella, \& Bermúdez-Humarán, 2014). The main genera found as common inhabitants of the gut are Bacteroides, Eubacterium, Ruminococcus, Clostridium, and Bifidobacterium, and, as subdominant microbiota, Escherichia coli, Veillonella, Staphylococcus, Proteus, Streptococcus, and Lactobacillus (Tannock, 2003; Mitra et al., 2013).

The fermentation of dietary fiber for the formation of short-chain fatty acids that act as carbon source for 
colonocytes, the synthesis of vitamins or the modulation of bioactive food components are among the main metabolic activities carried out by the intestinal microbiota. Its function shapes the host gut mucosal immune system and also the anatomy of the intestine (Moreau \& Gaboriau-Routhiau, 2000). Its adequate balance determines health and disease (Blaut \& Clavel, 2007), being the intestinal microbiota even considered as, at least partially, responsible for obesity and autism (Cotillard et al., 2013; Kang et al., 2013). The members of the intestinal microbiota can be classified on the basis of whether they exert pathogenic activities, pathogenic and health-promoting activities at the same time or exclusively health-promoting activities (Gibson, Rastall, \& Fuller, 2003). Species from the genera Bifidobacterium and Lactobacillus, commonly found within the normal human intestinal microbiota in healthy subjects, have been always considered health-promoting bacteria. These genera have been the source of the main strains used in food or in pharmaceutical preparations with health purposes, the so-called probiotics.

The definition of probiotic bacteria with most acceptance by the international scientific community is perhaps the one adopted by the joint FAO/WHO working group (FAO/WHO, 2002), which states that probiotics are "live microorganisms which when administered in adequate amounts confer a health benefit on the host". This joint commission released this definition after a meeting of experts held in Córdoba (Argentina) in October 2001. The following species, have been screened for the isolation of specific strains with health promoting effects: Lactobacillus casei, L. paracasei, L. rhmanosus, L. acidophilus, L. gasseri, L. johnsonii, L. plantarum, L. reuteri, L. crispatus, L. fermentum, Bifidobacterium bifidum, B. adolescentis, B. lactis, B. breve, B. infantis, B. longum, Saccharomyces boulardii and $S$. cerevisiae, among others. Enterococcus faecium strains have been also considered, however, concerns were raised about their use as probiotics, as their role in disease and the possibility of transfer of antibiotic resistance are still matter of debate for use in humans (Franz, Stiles, Schleifer, \& Holzapfel, 2003; Kayser, 2003; Rinkinen, Jalava, Westermarck, Salminen, \& Ouwehand, 2003; Tan et al., 2013).

As Bifidobacterium and Lactobacillus are naturally inhabitants of the human intestinal microbiota, some strains have a satisfactory tolerance to the gastrointestinal transit, good survival in food or pharmaceutical supplements and only health-promoting effects, then, the strategy of probiotic supplementation is the reinforcement of the intestinal microbiota, at least transitory, with health-promoting bacteria to benefit the intestinal balance. Additionally, strains for probiotic use, mainly from the genus Lactobacillus, can be isolated from artisanal fermented products such as fermented milks, cocoa grains, cheeses, sausages or cereal-based fermented foods (Farnworth, 2008), as bifidobacteria poorly tolerate oxygen and do not naturally occur in those food products.

\section{Oral Delivery of Probiotic Bacteria: Pharmaceutical Preparations and Fermented Milks as Food Vehicles}

Pharmaceutical preparations of probiotic bacteria consist of single or mixed strains commercialized under dehydrated form, usually achieved by freeze-drying, using a vast variety of cryoprotectors. These preparations are commonly maintained at room temperature and then they must tolerate sometimes harsh conditions for long periods of time (the shelf life of these products is frequently of several months). During this period, temperature and the water activity of the product are key variables to warrant the viability of the probiotics contained in the pharmaceutical preparation (Neha, Kamaljit, Ajay, \& Tarun, 2012). An issue that may present this type of preparations is the lack of proper identification of the specific strain/s contained in the product (generally species or only the genera are declared in the label), then impairing tracing the human clinical trials that support their probiotic properties.

Fermented dairy products, especially fermented milks, are food products massively and intensively used for the delivery of probiotics, due to several nutritional, technological and commercial reasons. First, certain probiotics (mainly those derived from the genera Lactobacillus) have been isolated from artisanal fermented milks, and it is generally thought that "closely related bacteria would perform well together", that is to say starter lactobacilli might get along well with intestinal lactobacilli, although this argument is not always verified for some starter culture-probiotic strain combinations (Joseph, Dave, \& Shah, 1998; Vinderola, Mocchiutti, \& Reinheimer, 2002). Additionally, yogurt is recognized as a healthy product by consumers, making it an attractive choice as a carrier for probiotics since it is largely incorporated in the daily diet of many consumers searching for a healthier way of life. For the industrial manufacture of yogurt containing probiotic bacteria, conventional yogurt processing procedures can be applied, with the probiotic bacteria being added prior to fermentation (set yoghurt), simultaneously with yogurt cultures, or after fermentation to the cooled product before packaging (stirred yoghurts). The methods used to manufacture stirred and drinking yogurt, in particular, are well suited to the addition of probiotics after fermentation (Stanton et al., 2003). There are many reports about the successful survival of probiotics in fermented milks during refrigerated storage (Vinderola, Bailo, \& Reinheimer, 2000; Kailasapathy, 2006), as these products have a shorter shelf life (1-2 months) compared to pharmaceutical preparations and they are stored at lower 
temperatures $\left(5-8^{\circ} \mathrm{C}\right.$ in the refrigerator) compared to products in pharmacy (room temperature on shelves).

\section{Health Benefits of Probiotics: Is There a Role Against Mycotoxins and Their Deleterious Effects?}

Some of the health benefits of the consumption of probiotic bacteria as pharmaceutical preparations or in fermented dairy products are the beneficial modulation of the gut microbiota activity by the reduction of the risk associated with mutagenicity and carcinogenicity, alleviation of lactose intolerance, reinforcement of gut mucosal immunity, acceleration of intestinal mobility, hypocholesterolemic effect, prevention or shortening of the duration of different diarrheas or respiratory infections, prevention of inflammatory bowel disease (IBD) and pouchitis, prevention of colon cancer, inhibition of Helicobacter pylori and intestinal pathogens or treatment and prevention of allergy, among other effects sustained by human clinical trials (Soccol et al., 2010; Sanders et al., 2014). A detailed discussion of these health benefits, the strains involved and the mechanism of action is beyond the scope of this review. However, it is likely that the beneficial effects achieved by the oral administration of probiotics are due to a combination of several mechanisms, in a strain dependent way, once probiotics arrive to the intestine, preferably as viable cultures as cell viability was shown to be important for cell functionality (Ouwehand \& Salminen, 1998; Kataria, Li, Wynn, \& Neu, 2009). Some of the mechanisms reported for probiotic bacteria so far are the competition for nutrients with enteropathogens, bioconversion of available sugars to acids (lowering the intestinal $\mathrm{pH}$ and inhibiting pathogens), production of vitamins and butyric acid (that acts as fuel for enterocytes for an enhanced intestinal barrier), competitive exclusion for adhesion sites (barrier function of the intestinal ephitelium) and the beneficial immunostimulation of the gut-associated limphoid tissue (Oelschlaeger, 2010). The main mechanism of action for the majority of the health benefits ascribed to probiotic bacteria is perhaps the adequate activation of the gut-associated immune response (Hardy, Harris, Lyon, Beal, \& Foey, 2013). For this, the specific strain, the food matrix used as a vehicle, the dose and the period and way of administration (continuous or in a cyclical way) seems to be crucial for the achievement of the desired health-benefit.

Mycotoxins are secondary metabolites produced naturally by filamentous fungi during late stationary growth phase, which are considered toxic substances when present in food for humans and feed for animals. They are frequently found in products such as nuts, corn, rice, and several other cereals, which can be contaminated in the field during harvest or storage. Studies have demonstrated their toxigenic, nephrotoxic, hepatotoxic, carcinogenic, immunosuppressive and mutagenic characteristics, and most mycotoxins represent a considerable risk to human and animal health (Bezerra da Rocha, Oliveira Freire, Feitosa Maia, Florindo Guedes, \& Rondina, 2014). The three major genera of mycotoxin-producing fungi are Aspergillus, Fusarium, and Penicillium (Groopman, Kenslerand, \& Wu, 2013) whereas the main mycotoxins present on food are aflatoxins, ochratoxins, fumonisins, trichothecenes and zearalenona (Zain, 2011). Mycotoxicoses, like other toxicological syndromes, can be considered as acute or chronic. Acute toxicity generally has a rapid onset of symptoms and an obvious toxic response, while chronic toxicity is characterized by low-dose exposure over a long time period, resulting in DNA damage, cancers and other generally irreversible effects (James, 2005). According to the present knowledge derived from the studies conducted on the role of probiotic bacteria against mycotoxins or against their detrimental effects, it is on the prevention or on the restoration of the chronic damage caused by mycotoxins where probiotics might have a role, considering some in vitro (liquid media and cell culture) and in vivo studies (animal and human trials) reported so far and that are revised below.

\section{In vitro Studies: Pure Cultures of Probiotics in Test Tubes and Exposed to Biological Fluids (Simulated Gastric Fluid, Bile Salts and Intestinal Mucus)}

Beginning with the pioneer studies conducted by Hani El-Nezami during his Ph.D. thesis (Mykkänen, Gratz, \& El-Nezami, 1998), from that moment on a series of in vitro studies were reported on the capacity of different strains of lactic acid bacteria to bind mycotoxins, mainly aflatoxins, suspended in liquid medium. The ability to bind Aflatoxin $\mathrm{B}_{1}\left(\mathrm{AFB}_{1}\right)$ was determined for 5 lactobacilli strains (including the widely commercially available $L$. rhamnosus GG (LGG) and L. casei Shirota), Propionibacterium freudenreichii ssp. shermanii JS and an Escherichi coli strain. Strains were suspended $\left(10^{10} \mathrm{CFU} / \mathrm{ml}\right)$ in a $5 \mu \mathrm{M}$ solution of the mycotoxin. It was shown that aflatoxin binding was fast (removal from the supernantant was already observed by time zero of contact) and stable (almost no differences in removal, measured as percent of original concentration, was observed after 4, 24, 48 and $72 \mathrm{~h}$ of contact of the strains with $\mathrm{AFB}_{1}$ ). However, it is worth to mention that significant reduction in $\mathrm{AFB}_{1}$ concentration in the supernatant was achieved when cells were present at high concentrations, at least $2 \times 10^{9}$ $\mathrm{CFU} / \mathrm{ml}$. Binding was also shown to be independent from cell viability as viable and heat-inactivated cells rendered the same $\mathrm{AFB}_{1}$ removal (El-Nezami, Kankaanpaa, Salminen, \& Ahokas, 1998). In particular, Haskard, Binnion, and Ahokas (2000) deepened the studies on the capacity of late exponential-early stationary phase LGG cells to bind $\mathrm{AFB}_{1}$. It was shown that viable, heat-killed and acid-killed LGG responded in a similar manner. In line with these results, Topcu, Bulat, Wishah, and Boyac (2010) confirmed that viability of the 
bacteria did not have any significant effect on the detoxification of $\mathrm{AFB}_{1}$ and patulin by two enterococci strains. In the work of Haskard et al. (2000), the effects of pronase E, lipase and m-periodate on $\mathrm{AFB}_{1}$ binding and release were consistent with $\mathrm{AFB}_{1}$ binding predominantly to carbohydrate components of the bacteria. The effect of urea suggested that hydrophobic interactions play a major role in binding. However, an increase in $\mathrm{pH}$ from 2.5 to 8.5 had no effect on $\mathrm{AFB}_{1}$ binding. Peltonen, El-Nezami, Haskard, Ahokas, and Salminen (2001) suggested that binding might be very variable among strains followed a study that comprised 20 species/strains of lactococci, lactobacilli and bifidobacteria. Again, cells were suspended at $10^{10} \mathrm{CFU} / \mathrm{mL}$ in the presence of 5 $\mu \mathrm{M}$ of $\mathrm{AFB}_{1}$. In the mentioned study, $\mathrm{AFB}_{1}$ bound ranged from 5.6 to $48.7 \%$ of its original concentration, depending on the strain considered. Binding was shown to be reversible as $\mathrm{AFB}_{1}$ was released by 5 successive aqueous washes in 2 out of 3 strains subjected to repeated washing. On the contrary, binding was shown to be stable after successive washing in the works of Hernandez-Mendoza, Garcia, and Steele (2009) and Topcu et al. (2010), where 3 washes were performed. Although hydrophobicity was indicated as having a major role on aflatoxins binding (Haskard et al., 2000), the strain showing highest hydrophobicity (measured as adhesion to p-xylene) was not the one with the highest $\mathrm{AFB}_{1}$ binding capacity, when LGG, L. rhamnosus LC705, Propionibacterium freudenreichii ssp. shermanii JS and Bifidobacterium breve Bbi99/E8 were compared for hydrophobicity and $\mathrm{AFB}_{1}$ binding capacity (Halttunen, Collado, El-Nezami, Meriluoto, \& Salminen, 2008). It is also interesting to note that the toxin-removal capacity of the combination of the 4 strains was not the sum of their individual capacities. The removal of other mycotoxins beyond $\mathrm{AFB}_{1}$ by lactic acid bacteria and bifidobacteria was studied as well. Thirty cultures, including strains from the same species, were suspended $\left(5 \times 10^{9} \mathrm{CFU} / \mathrm{ml}\right)$ in the presence of $0.5-1 \mu \mathrm{M}$ of patulin (PAT) or ochratoxin (OTA). As observed for $\mathrm{AFB}_{1}$, removal capacity was variable among strains (reduction in the supernatant ranged from 2 to $82 \%$ ) and depending on the strain-mycotoxin considered as well, but not too much on PAT or OTA concentration. For instance, $B$. animalis VM12 reduced $82 \%$ of PAT and $22 \%$ of OTA whereas $B$. animalis LA17 reduced less than $12 \%$ of both toxins. On the contrary, some B. longum, L. acidophilus and L. plantarum strains reduced much more OTA than PAT (Fuchs et al., 2008). The strain-specific capacity to bind $\mathrm{AFB}_{1}$ was confirmed by Hernandez-Mendoza et al. (2009) where the removal capacity ranged from ca $14-50 \%$ among 8 strains of $L$. case $i$ assessed.

To this point, in vitro studies were conducted using highly-concentrated cell suspensions $\left(0.5-1 \times 10^{10} \mathrm{CFU} / \mathrm{mL}\right)$, that is to say, pure cell cultures not included in a food matrix. Mateo, Medina, Mateo, \& Jiménez (2010) studied the capacity of Oenococcus oeni $6 \mathrm{G}$ to grow and to remove OTA $(2-5 \mu \mathrm{g} / \mathrm{L})$ in a synthetic culture medium that imitated the composition of wine after alcoholic fermentation, where 5,10 or $15 \%(\mathrm{w} / \mathrm{w})$ of ethanol was added. The highest toxin removal percentage (maximum 30\%) was observed in cultures containing 5\% ethanol and 2 $\mu \mathrm{g} / \mathrm{L}$ of OTA at the beginning of the culture (achieved by day 5 of incubation at $28{ }^{\circ} \mathrm{C}$, moment at which the strain attained ca. $2 \times 10^{8} \mathrm{CFU} / \mathrm{mL}$ ). Studies were conducted also in skim milk as food matrix (Serrano-Niño et al., 2013). The effects of L. acidophilus NRRL B-4495, L. reuteri NRRL B-14171, L. rhamnosus NRRL B-442, $L$. johnsonii NRRL B-2178 and B. bifidum NRRL B-41410 on aflatoxin M1 (AFM $\left.)_{1}\right)$ were assessed in skim milk containing $1-2 \times 10^{9} \mathrm{CFU} / \mathrm{mL}$ of viable cells of each strain and subjected to a simulated gastrointestinal digestion. The percentage of $\mathrm{AFM}_{1}$ removal was strain dependent being the bifidobacteria strain used the culture with the highest removal capacity (ca. $45 \%$ of AFM1 reduced after the simulated digestive process).

As regard the effect of $\mathrm{pH}$ on mycotoxins binding, results seems to be contradictory or, may be, strain-mycotoxin combination dependent. In the work of Haskard et al. (2000), modifying pH from 2.5 to 8.5 had no effect on $\mathrm{AFB}_{1}$ binding to LGG. However, Fuchs et al. (2008) showed that binding was much more effective at $\mathrm{pH} 5$ compared to $\mathrm{pH} 7$ or 8 for removal of PAT and OTA from liquid medium by B. animalis VM12 and L. acidophilus VM20, respectively. The results of Topcu et al. (2010) are somehow located between these previous reports since, for one strain $\mathrm{AFB}_{1}$ binding was not $\mathrm{pH}$-dependent ( $\mathrm{pH}$ range 3-7), whereas PAT binding was higher at higher $\mathrm{pH}$ values, while the opposite situation (binding higher at lower $\mathrm{pH}$ ) was observed for the other strain.

The capacity and nature of Fumonisin B1 removal by two strains of Saccharomyces cerevisiae and L. acidophilus was also reported. It was confirmed that the removal was fast and reversible, cell viability was not necessary and the amount of FB1 removed was both toxin- and microorganism concentration-dependent. It was also reported that the process did not involve chemical modification of FB1 molecules and that cell wall structural integrity of the microorganisms was required for removal (Pizzolitto, Salvano, \& Dalcero, 2012).

Probiotic bacteria used for food applications may have human origin (feces, breast milk) or they can be derived from food (artisanal fermented products) (Fontana, Bermudez-Brito, Plaza-Diaz, Muñoz-Quezada, \& Gil, 2013). It was much debated where one or other origin would have importance on the probiotic property (giving raise to the species-specific criterium). In this sense, Hamidi et al. (2013), found similar binding capacities of $\mathrm{AFB}_{1}$ in 
two strains of Lactobacillus pentosus and Lactobacillus brevis isolated from human feces and milk samples, respectively. However, Hernandez-Mendoza et al. (2009) studied the $\mathrm{AFB}_{1}$ binding capacity using 8 strains of $L$. casei of human and food origin, observing that in general, the human isolates bound the most $\mathrm{AFB}_{1}$ and the cheese isolates the least, reinforcing perhaps the importance of the species-specificity on this issue.

The studies discussed so far were conducted using highly-concentrated cell suspensions put directly in contact with different mycotoxins in buffer solutions or, to a lesser extent, cells contained into food matrixes (wine, skim milk) using perhaps more realistic (lower) cell concentrations (those normally found in food carrying lactic acid starter or probiotic bacteria). It is also important to determine the effects of biological fluids found by probiotic cells and mycotoxins along the intestinal transit, such as gastric acidity, bile salts and intestinal mucus. In this sense, it was demonstrated that probiotic cells can still possess mycotoxins binding capacity after (at least simulated) gastrointestinal digestion (Dogi et al., 2011; Serrano-Niño et al., 2013). A more sophisticated approach was used to study the fate of the Fusarium-produced Beauvericin (BEA) in the presence of several dietary fibers (galactomanan, glucomannan, citrus fiber, bamboo fiber, carrot fiber, pie fiber, b-glucan, xilan, and cellulose) and bifidobacteria and lactobacilli strains (Mallebrera, Meca, Manyes, Mañes, \& Font, 2013). Three sequential steps were used to simulate gastrointestinal digestion until the colon: an initial saliva/pepsin/ $\mathrm{HCl}$ digestion for $2 \mathrm{~h}$ at $37{ }^{\circ} \mathrm{C}$ at $\mathrm{pH} 2$ (mouth and gastric conditions), followed by digestion with bile salts/pancreatin for $2 \mathrm{~h}$ at $37^{\circ} \mathrm{C}$ (duodenal digestion) and finally the colonic conditions were simulated by adding some bacteria representative of the gastrointestinal tract to the duodenal simulated fluid. It was observed that the reduction of BEA bioaccessibility in the experiments carried out using the fiber compounds ranged from 60 to $80 \%$, whereas in the trials carried out using microbial strains the bioaccessibility observed ranged from 30 to $85 \%$. After leaving the stomach, ingested cells are exposed to bile salts. Hernandez-Mendoza et al. (2009) studied the effects of bile exposure (up to $0.15 \% \mathrm{w} / \mathrm{v}$ ) on the $\mathrm{AFB}_{1}$ binding capacity using $8 \mathrm{~L}$. casei strains of human and food origin. Results showed that exposure to bile significant increased $\mathrm{AFB}_{1}$ binding for some strains (for instance, for the strain with lowest binding capacity, removal increased from ca. $18 \%$ to $60 \%$ ) whereas for strains with higher removal capacity changes were less noticeable. Additionally, the original differences in binding capacity between the strains (in the absence of bile) were reduced after $0.15 \%(\mathrm{w} / \mathrm{v})$ bile exposure.

Followed gastric digestion and bile exposure, ingested cells arrive to the small intestine were they must interact with intestinal mucus. Gratz et al. (2004) studied the effects of preincubation of two probiotic preparations with either $\mathrm{AFB}_{1}$ or mucus on the ability of LGG and L. rhamnosus LC-705 to bind $\mathrm{AFB}_{1}$ in vitro. Interference in surface binding was assessed in two assays, either by allowing bacteria to bind $\mathrm{AFB}_{1}$ first and subsequently incubating them with mucus or by allowing bacteria to bind mucus first and then incubating them with $\mathrm{AFB}_{1}$ (increasing concentrations up to $70 \mu \mathrm{M}$ ). Intestinal mucus from porcine colon samples was used at different concentrations ( 1 to $10 \mathrm{mg} / \mathrm{ml}$ ). Preincubation of probiotic cells with $\mathrm{AFB}_{1}$ reduced the adhesion of the probiotic-mycotoxin complex to mucus. At the same time, preincubation of probiotics with mucus reduced the amount of $\mathrm{AFB}_{1}$ bounded. Authors concluded on the importance of these, as probiotics adhering to the intestinal wall are less likely to bind and consequently accumulate $\mathrm{AFB}_{1}$ in the host (may be this conclusion might be extrapolated to the resident intestinal microbiota). On the other hand, probiotics with $\mathrm{AFB}_{1}$ bound to their surfaces are less likely to adhere to the intestinal wall, reducing then the exposure of the epithelium to dietary $\mathrm{AFB}_{1}$.

\section{In vitro Studies: Cell Lines in Co-Culture With Probiotics and Mycotoxins}

Conclusions derived from in vitro experiments about probiotic-mycotoxin interaction would be more realistic if a third player is on the scene: the epithelial cells that separate the luminal contents from the intestinal lamina propria and inner tissues. This might be achieved by the use of eukaryotic epithelial cell lines in culture with probiotics and mycotoxins. Gratz et al. (2007) demonstrated that LGG reduces $\mathrm{AFB}_{1}$ transport, metabolism and toxicity in Caco- 2 cells. In this cell line, grown as confluent monolayers on transmembrane filters, $\mathrm{AFB}_{1}$ transport from the apical to the basolateral chamber was reduced almost to the half within the first hour of incubation with LGG $\left(1-5 \times 10^{10} \mathrm{CFU} / \mathrm{mL}\right)$. LGG bound $40-61.0 \%$ of added $\mathrm{AFB}_{1}(150 \mu \mathrm{M})$. As a detrimental effect on Caco-2 cells upon $\mathrm{AFB}_{1}$ exposure (24-72 $\mathrm{h}$ ), it was observed that the mycotoxin presence caused significant reduction in transepithelial resistance. However, coincubation with $1 \times 10^{10} \mathrm{CFU} / \mathrm{ml}$ of LGG after $24 \mathrm{~h}$ protected against $\mathrm{AFB}_{1}$-induced reductions in transepithelial resistance. DNA fragmentation was apparent in eukaryotic cells treated only with $\mathrm{AFB}_{1}$ cells but not in cells coincubated with LGG. $\mathrm{LGG}$ reduced $\mathrm{AFB}_{1}$ uptake and protected against both membrane and DNA damage in the Caco-2 model. Further information on the positive effects of LGG on Caco-2 cells exposed to mycotoxins was provided by the work of Turner et al. (2008), this time using Deoxynivalenol (DON) as toxic fungal metabolite. This in vitro study evaluated whether LGG could restore the differentiation process, using alkaline phosphatase (ALP) activity as a marker of differentiation. DON exposure $(200 \mathrm{ng} / \mathrm{mL})$ 
caused a significant $36 \%$ reduction in ALP activity compared to untreated cells. A dose-dependent restoration of ALP activity was observed when DON treated cells were co-incubated with heat inactivated LGG. Higher restoration was observed with increasing doses of LGG $\left(1 \times 10^{4} \mathrm{CFU} / \mathrm{mL}, 1 \times 10^{7} \mathrm{CFU} / \mathrm{mL}\right.$ and $\left.1 \times 10^{10} \mathrm{CFU} / \mathrm{mL}\right)$. Co-incubation of the non-binding DON strain, L. rhamnosus LC-705 $\left(1 \times 10^{10} \mathrm{CFU} / \mathrm{mL}\right)$, with DON did not significantly restore ALP activity compared to DON-only treated cells. When viable LGG cells were co-incubated with DON a similar restoration of ALP activity was observed as seen for heat inactivated LGG cells. These combined data suggest that the major effect of LGG on restoring ALP activity, and therefore Caco-2 cell differentiation, was due to specific binding of DON, with possibly a less significant role of non-specific bacterial interference. Finally, in order to investigate the response that immune cells can exert upon mycotoxin exposure, Mechoud, Juarez, Font de Valdez, and Rodriguez, (2012) evaluated the ability of $L$. reuteri CRL 1098 and $L$. acidophilus CRL 1014 to prevent OTA effects on TNF- $\alpha$ and IL-10 production and apoptosis induction in human peripheral blood mononuclear cells (PBMC). L. reuteri reduced by $29 \%$ the OTA inhibition of TNF-a production whereas $L$. acidophilus increased 8 times the TNF- $\alpha$ production by OTA treated-PBMC. Also, both bacteria reversed apoptosis induced by OTA by $32 \%$. However, neither of the bacteria reversed the OTA inhibition on IL-10 production.

\section{In vivo Studies: Animal Trials}

Preclinical trials conducted in animals might give an insight on the mechanism underlying the positive effects ascribed to probiotics and pave the way to human clinical trials. A series of experiments using mice, rats, poultry and pigs were conducted in order to assess the in vivo fate of ingested mycotoxins and probiotics, and the effects on some biological parameters related to health and disease. In a study conducted in rats, animals received LGG $\left(5 \times 10^{10} \mathrm{CFU}\right.$ in $\left.0.5 \mathrm{ml} \mathrm{PBS}\right)$ by oral gavage daily for 3 days before and 3 days after a single oral dose of $\mathrm{AFB}_{1}(1.5$ $\mathrm{mg}$ or $4.8 \mu \mathrm{mol} / \mathrm{kg}$ of body weight). As expected from previous in vitro experiments, fecal $\mathrm{AFB}_{1}$ excretion in LGG-treated rats was increased via bacterial $\mathrm{AFB}_{1}$ binding. Additionally, $\mathrm{AFB}_{1}$-associated growth faltering and liver injury were alleviated with LGG administration (Gratz et al., 2006). Another study conducted in rats for 4 weeks showed the capacity of $L$. casei $\mathrm{L} 1$ and $L$. reuteri $\mathrm{L} 2\left(10^{12} \mathrm{CFU} / \mathrm{kg}\right.$ b.w.) to protect against the oxidative stress when animals were fed $\mathrm{AFB}_{1}$-contaminated diet ( $3 \mathrm{mg} / \mathrm{kg}$ diet) (Hathout et al., 2011). In general, animals studies are performed delivering mycotoxins by the oral route. However, it caught our attention a study conducted in 4-weeks rats were animals received $\mathrm{AFB}_{1}$ intraperitonally $(450 \mu \mathrm{g} / \mathrm{kg}$ body weight twice a week for 6 weeks) along with the oral administration for 24 weeks of milk fermented by both LGG and L. casei Shirota. By week $25^{\text {th }}$ it was observed a one third reduction of tumor incidence in animals that received the fermented milk as well as a reduction in DNA damage as revealed by the comet assay (Kumar et al., 2011, 2012).

Madrigal-Santillán, Madrigal-Bujaidar, Márquez-Márquez, and Reyes. (2006) fed mice with $\mathrm{AFB}_{1}$ contaminated corn at two levels ( 0.4 and $0.8 \mathrm{mg} / \mathrm{kg}$ ), along with (or without) a strain of Saccharomyces cerevisiae $\left(10^{8} \mathrm{CFU} / \mathrm{g}\right.$ of diet). Weight and the frequency of micronucleated normochromatic erythrocytes (MNNE), an indicator of genotoxicity, was determined weekly for six weeks. It was observed that control and S. cerevisiae fed mice had similar constant weight increase, and low MNNE rate, whereas mice fed only $\mathrm{AFB}_{1}$ showed weight decrease and significant MNNE increase. S. cerevisiae inclusion in the diet improved weight gain and reduced MNNE produced by $\mathrm{AFB}_{1}$.

Assessment of the role of probiotics on the restoration of biological functions was also studied in poultry that deliberately received a mycotoxin-contaminated diet. Decreased genotoxicity of faecal waters, derived from chickens fed with $\mathrm{AFB}_{1}$ contaminated fodder $(1-5 \mathrm{mg} / \mathrm{Kg})$ and a probiotic-plant extract preparation $\left(10^{10} \mathrm{CFU}\right.$ of $L$. paracasei LOCK 0920, L. brevis LOCK 0944 and L. plantarum LOCK 0945, $10^{6}$ CFU of S. cerevisiae LOCK 0140 and Yucca schidigera extract), was observed on human peripheral blood lymphocytes (Slizewska, Nowak, Libudzisz, \& Blasiak, 2010). The aerobic spore-forming Brevibacillus laterosporus, a species less exploited as probiotic, was used in the study of Bagherzadeh Kasmani, Karimi Torshizi, Allameh, \& Shariatmadari (2012) in Japanese quail. Animals received diet contaminated with AFB1 $(2.5 \mathrm{mg} / \mathrm{kg})$, supplemented (or not) with $B$. laterosporus $\left(10^{8} \mathrm{CFU} / \mathrm{mL}\right)$. Feeding $\mathrm{AFB}_{1}$ alone to chicks resulted in a significant decrease in serum albumin, total protein, and glucose and cholesterol levels but a significant increase in serum uric acid, urea, creatinin and phosphorus. Treatment of birds on $\mathrm{AFB}_{1}$ with the probiotic candidate restored these parameters to their original levels. Another spore-forming microorganism, Bacillus subtilis ANSB060 was used to study the egg quality, biochemical and histopathological changes in layers that received $\mathrm{AFB}_{1}$-contaminated corn for 6 weeks. Improved eggshell strength was observed in animals that received the bacilli. Additionally, B. subtilis ANSB060 enhanced the activity of antioxidant enzymes, and it recovered the protein synthesis in liver. Moreover, B. subtilis ANSB060 also ameliorated the damage of liver and kidney tissue and restored them to normal (Ma et al., 2012). S. cerevisiae CECT 1891 was reported as an antiaflatoxicogenic agent in broiler feedstuffs (Pizzolitto, Armando, Salvano, 
Dalcero, \& Rosa, 2013). Chickens received $1.2 \mathrm{mg}$ of $\mathrm{AFB}_{1} / \mathrm{kg}$ of feed for 3 weeks, and the yeast strain was administrated in feed $\left(10^{10} \mathrm{CFU} / \mathrm{kg}\right)$, in the drinking water $\left(5 \times 10^{9} \mathrm{CFU} / \mathrm{L}\right)$, or as a combination of both treatments. $\mathrm{AFB}_{1}$ significantly decreased the body weight gain and feed intake, and impaired feed conversion rate. Moreover, $\mathrm{AFB}_{1}$ treatment decreased serum protein concentration and increased liver damage. The addition of $S$. cerevisiae CECT 1891 showed a protective effect on the relative weight of the liver and on histopathology and biochemical parameters. Furthermore, dietary addition of the yeast to drinking water alleviated the negative effects of $\mathrm{AFB}_{1}$ on growth performance parameters.

However, it must be acknowledged that not all animal trials resulted in encouraging results about the positive role of probiotics on the restoration of mycotoxins damage. For instance, no absorption prevention and toxicity diminution was observed in a 35 day trial performed in piglets in order to examine the effects of feeding a DON-contaminated diet in the absence or presence of two strains of B.subtilis and B. licheniformis on performance, blood concentration of DON and on liver function. One may think that the, rather low, dose of bacilli administered $\left(2.3 \times 10^{6} \mathrm{CFU} / \mathrm{g}\right.$ diet) might be perhaps the cause of the absence of positive effects (Dänicke \& Döll, 2010).

\section{In vivo Studies: Human Clinical Trials}

Due to obvious ethical concerns, human clinical trials involving mycotoxins and probiotics cannot be performed by deliberately administering mycotoxins to human volunteers along with probiotics. However, some populations more than others, are currently exposed to mycotoxins as they consume foods where these fungal metabolites occur naturally (milk, cheese, cream, yoghurt, peanut, nut confectionary, bread, wheat, pasta, rice, bread, beans, noodles). A pilot clinical trial was carried out in Egypt to investigate the effect of a probiotic preparation containing L. rhamnosus LC-705 and P. freudenreichii spp. shermanii JS on the levels of AFB $_{1}$ in faecal samples from 20 healthy volunteers. The study involved 3 distinct periods: 1-week baseline, 2-weeks supplementation and 1 -week follow-up period. The faecal samples of 11 of the recruited 20 volunteers were positive for $\mathrm{AFB}_{1}$ with levels ranging between 1.8 and $6 \mu \mathrm{g} \mathrm{AFB}_{1} / \mathrm{kg}$ feces. For volunteers who were administered the probiotic preparation, there was a significant reduction in the level of $\mathrm{AFB}_{1}$ after the second week of the trial, a reduction which continued during the follow-up period (El-Nezami et al., 2000). According to the study performed in rats by Gratz et al. (2006), one might have expected that people consuming probiotics would have had an increased elimination of $\mathrm{AFB}_{1}$ in feces due to binding of probiotics with $\mathrm{AFB}_{1}$ and the fecal elimination of the complex. Authors explained that this apparently contradictory finding might be due to the use of fecal aflatoxin as a biomarker of mycotoxin exposure and by the timing of fecal collection (one sample 1 week after starting the probiotic administration). The fecal level reflects both the dietary $\mathrm{AFB}_{1}$ and that secreted via bile, and then it would not be an optimal biomarker for dietary exposure. Interaction between the probiotic and aflatoxins probably removed most of the luminal aflatoxin immediately after starting the bacterial supplementation. After 1 week the fecal level in the group that received probiotics reflects mainly the current dietary exposure while that in the control group represents both the aflatoxin secreted via bile and current dietary exposure (Mykkänen et al., 2011). However, we cannot rule out the possibility that the probiotic-mycotoxin complex had been internalized in the lamina propria and had been made available to the inner tissues, since probiotics attached to epithelial cells or present in the gut lumen are sampled by dendritic cells and internalized into lamina propria or are uptaken by $\mathrm{M}$ cells on Peyer's patches in order to interact with the immune cells of the lamina propria to launch their immune response (Vinderola, Medici, \& Perdigón, 2004; Beyaz, Bayraktaroğlu, \& Ergün, 2010; Burns, Reinheimer, \& Vinderola, 2011). Then, further in vivo studies should be conducted in order to determine whether there might be deposition and accumulation of mycotoxins, carried out by probiotics attached to their cell wall, in internal organs or lymphoid tissue such as mesenteric lymph nodes, liver and spleen. Additionally, the possible role of the intestinal microbiota should be also studied in order to determine their contribution to a natural decontaminating mechanism carried out by lactobacilli and bifidobacteria naturally present the gut. The comparison of the effects of mycotoxins administered to germ-free mice and to conventional animals might give a useful insight in order to hypothesize on the role of the resident microbiota on mycotoxin decontamination.

Another human clinical trial was conducted by the same research group involving ninety healthy Chinese young men that received a placebo or the same strains as in the previous study 2 times/d for 5 weeks (El-Nezami et al., 2006). The subjects provided 4 urine samples: at baseline, at 3 and 5 weeks after starting the supplementation and at the end of the 5-weeks post intervention period. Urinary excretion of the adduct aflatoxin B1-N7-guanine (AFB-N7-guanine) was used as a marker for a biologically effective dose of $\mathrm{AFB}_{1}$. An increased risk of liver cancer is associated with an elevated urinary excretion of this aflatoxin-DNA adduct (Qian et al., 1994). The percentage of samples with negative AFB-N7-guanine values tended to be higher in the group that received probiotics compared to the control group during the 5-weeks intervention period, and a statistically significant decrease in the concentration of urinary AFB-N7-guanine was observed in the probiotic group (36\% reduction at 
week 3 and $55 \%$ at week 5).

\section{Concluding Remarks}

It has been more than 15 years already that scientific evidence has been gathering on the possible role of probiotics on mycotoxins removal and damage restoring. The first studies demonstrated that different lactobacilli and bifidobacteria strains can reversibly bind mycotoxins due to, mainly, hydrophobic interactions, being this interaction dependent on temperature and cell concentration and, for some strains, also dependent on $\mathrm{pH}$. It must be noticed that in vitro binding tests have been conducted with probiotic cell concentrations generally much higher than those commonly found in fermented dairy products, the main food vehicle to deliver probiotics. Also, even when probiotics are available as highly concentrated pharmaceutical products, they will undergo dilution when ingested. This is to say that the high binding capacity of certain strains probiotics demonstrated in vitro, might be of less magnitude in vivo, simply due to the dilution phenomena by biological fluids during gastrointestinal transit. Interestingly, it was shown that binding to mycotoxins is a property that can be retained after gastric digestion. In cell lines, it was demonstrated that preincubation of probiotics with mycotoxins reduced the adhesion of the probiotic-mycotoxin complex to mucus and at the same time, preincubation of probiotics with mucus reduced the amount of mycotoxin bounded. Bile salt exposure was shown to increase $\mathrm{AFB}_{1}$ binding for some strains. Additionally, Caco- 2 cells were used to demonstrate that probiotics might reduce $\mathrm{AFB}_{1}$ transport and toxicity, they can also protect against $\mathrm{AFB}_{1}$-induced reductions in transepithelial resistance and DNA damage, and they can restore the differentiation process using alkaline phosphatase activity as a marker of differentiation. Prevention of apoptosis induction was also demonstrated in human peripheral blood cells. In animal trials, the effects of the oral administration of probiotics and mycotoxins were related to increased fecal excretion of mycotoxins, alleviation of liver injury, protection against oxidative stress, reduction of tumor incidence and DNA damage and restoration of different parameters related to animal health and production (for instance body weight and eggshell strength). Human clinical trials are still scarce and some, may be, not-expected results were observed in human trials, based on predictions from animal assays. These aparent contradictionssuggest then the need of further in vivo studies and the need of the determination of the presence of mycotoxins in internal organs (mesenteric lymph nodes, liver, spleen), possibly internalized binded to probiotics during their interaction with the immune cells of the gut. Fortunately, many encouraging results were observed in studies performed with the widely food and pharma available LGG strain, suggesting then that possibly many consumers around the world, naturally exposed to dietary mycotoxins, are already profiting the possible effective role of this strain, or other probiotic cultures, against the detrimental chronic damage caused by mycotoxins.

\section{Acnowledgements}

Authors are grateful to the program "Messaggeri della Conoscenza", project $\mathrm{N}^{\circ} 179$ entitled "Probiotic microorganisms for food and pharmacy applications. Microbiological, technological and functional aspects" of the Ministero dell'Universitá e della Ricerca (MIUR, Italy) for finantial support.

\section{References}

Bagherzadeh Kasmani, F., Karimi Torshizi, M. A., Allameh, A., \& Shariatmadari, F. (2012). A novel aflatoxin-binding Bacillus probiotic: performance, serum biochemistry, and immunological parameters in Japanese quail. Poultry Science, 91, 1846-53. http://dx.doi.org/10.3382/ps.2011-01830

Beyaz, F., Ergün, E., Bayraktaroğlu, A. G., \& Ergün, L. (2010). Identification of intestinal M cells in isolated lymphoid follicles and Peyer's patches of the Angora rabbit. Cell Tissue Research, 341, 417-27. http://dx.doi.org/10.1007/s00441-010-1005-5

Bezerra da Rocha, M. E., Oliveira Freire, F. C., Feitosa Maia, F. E., Florindo Guedes, M. I., \& Rondina, D. (2014). Mycotoxins and their effects on human and animal health. Food Control, 36, 159-165. http://dx.doi.org/10.1016/j.foodcont.2013.08.021

Blaut, M., \& Clavel, T. (2007). Metabolic diversity of the intestinal microbiota: implications for health and disease. Journal of Nutrition, 137, 751S-755S.

Burns, P., Reinheimer, J., \& Vinderola, G. (2011). Impact of bile salt adaptation of Lactobacillus delbrueckii subsp. lactis 200 on its interaction capacity with the gut. Research in Microbiology, 162, 782-90. http://dx.doi.org/10.1016/j.resmic.2011.07.005

Cotillard, A., Kennedy, S. P., Kong, L. C., Prifti, E., Pons, N., Le Chatelier, E., ... Ehrlich, S. D. (2013). Dietary intervention impact on gut microbial gene richness. Nature, 500, 585-8. http://dx.doi.org/10.1038/nature12480 
Dänicke, S., \& Döll, S. (2010). A probiotic feed additive containing spores of Bacillus subtilis and B. licheniformis does not prevent absorption and toxic effects of the Fusarium toxin deoxynivalenol in piglets. Food and Chemical Toxicology, 48, 152-158. http://dx.doi.org/10.1016/j.fct.2009.09.032

Dogi, C. A., Armando, R., Ludueña, R., A. de Moreno de LeBlanc, A., Rosa, C. A. R., Dalcero, A., \& Cavaglieri, L. (2011). Saccharomyces cerevisiae strains retain their viability and aflatoxin B1 binding ability under gastrointestinal conditions and improve ruminal fermentation. Food Additives and Contaminants, 28, 1705-1711.

El-Nezami, H., Kankaanpaa, P., Salminen, S., \& Ahokas J. (1998). Ability of dairy strains of lactic acid bacteria to bind a common food carcinogen, Aflatoxin B1. Food and Chemical Toxicology, 36, 321-326. http://dx.doi.org/10.1016/S0278-6915(97)00160-9

El-Nezami, H., Mykkanen, H., P., Kankaanpaa, P., Suomalainen, T., Salminen, S., \& Ahokas, J. (2000). Ability of a mixture of Lactobacillus and Propionibacterium to influence the faecal aflatoxin content in healthy Egyptian volunteers: a pilot clinical study. Bioscience Microflora, 19, 41-45. http://dx.doi.org/10.12938/bifidus1996.19.41

El-Nezami, H. S., Polychronaki, N. N., Ma, J., Zhu, H., Ling, W., Salminen, E. K., ... Mykkanen, H. M. (2006). Probiotic supplementation reduces a biomarker for increased risk of liver cancer in young men from Southern China. American Journal of Clinical Nutrition, 83, 1199-203.

FAO/WHO. (2002). Guidelines for the evaluation of probiotics in food. Food and Agriculture Organization of the United Nations and World Health Organization Working Group Report.

Farnworth, E. (2008). Handbook of fermented functional foods (2nd ed). Boca Raton, USA: CRC Press.

Fontana, L., Bermudez-Brito, M., Plaza-Diaz, J., Muñoz-Quezada, S., \& Gil, A. (2013). Sources, isolation, characterisation and evaluation of probiotics. British Journal of Nutrition, 109, S35-S50. http://dx.doi.org/10.1017/S0007114512004011

Franz, C. M., Stiles, M. E., Schleifer, K. H., \& Holzapfel, W. H. (2003). Enterococci in foods - a conundrum for food safety. International Journal of Food Microbiology, 88, 105-122. http://dx.doi.org/10.1016/S0168-1605(03)00174-0

Fuchs, S., Sontag, G., Stidl, R., Ehrlich, V., Kundi, M., \& Knasmuller, S. (2008). Detoxification of patulin and ochratoxin A, two abundant mycotoxins, by lactic acid bacteria. Food and Chemical Toxicology, 46, 1398-1407. http://dx.doi.org/10.1016/j.fct.2007.10.008

Gibson, G. R., Rastall, R. A., \& Fuller, R. (2003). The health benefits of probiotics and prebiotics. In R. Fuller \& G. Perdigón (Eds.), Gut flora, nutrition, immunity and health (pp. 52-76). Oxford, UK: Blackwell Publishing.

Gratz, S., Mykkanen, H., Ouwehand, A. C., Juvonen, R., Salminen, S., \& El-Nezami, H. (2004). Intestinal mucus alters the ability of probiotic bacteria to bind aflatoxin B1 in vitro. Applied and Environmetal Microbiology, 70, 6306-6308. http://dx.doi.org/10.1128/AEM.70.10.6306-6308.2004

Gratz, S., Taubel, M., Juvonen, R. O., Viluksela, M., Turner, P. C., Mykkanen, H., \& El-Nezami, H. (2006). Lactobacillus rhamnosus strain GG modulates intestinal absorption, fecal excretion, and toxicity of aflatoxin $\mathrm{B} 1$ in rats. Applied and Environmental Microbiology, 72, 7398-7400. http://dx.doi.org/10.1128/AEM.01348-06

Gratz, S., Wu, Q. K., El-Nezami, H., Juvonen, R. O., Mykkanen, H., \& Turner, P. C. (2007). Lactobacillus rhamnosus strain GG reduces aflatoxin B1 transport, metabolism, and toxicity in Caco-2 cells. Applied and Environmental Microbiology, 73, 3958-3964. http://dx.doi.org/10.1128/AEM.02944-06

Groopman, J. D., Kenslerand, T. W., \& Wu, F. (2013). Mycotoxins - Occurrence and toxic effects. Encyclopedia of Human Nutrition, 2, 337-341. http://dx.doi.org/10.1016/B978-0-12-375083-9.00122-7

Halttunen, T., Collado, M. C., El-Nezami, H., Meriluoto, J., \& Salminen, S. (2008). Combining strains of lactic acid bacteria may reduce their toxin and heavy metal removal efficiency from aqueous solution. Letters in Applied Microbiology, 46, 160-165. http://dx.doi.org/10.1111/j.1472-765X.2007.02276.x

Hamidi, A., Mirnejad, R., Yahaghi, E., Behnod, V., Mirhosseini, A., Amani, S., ... Darian, E. K. (2013). The aflatoxin B1 isolating potential of two lactic acid bacteria. Asian Pacific Journal of Tropical Biomedicine, 3, 732-736. http://dx.doi.org/10.1016/S2221-1691(13)60147-1

Hardy, H., Harris, J., Lyon, E., Beal, J., \& Foey, A. D. (2013). Probiotics, prebiotics and immunomodulation of gut mucosal defences: homeostasis and immunopathology. Nutrients, 5, 1869-1912. 
http://dx.doi.org/10.3390/nu5061869

Haskard, C., Binnion, C., \& Ahokas, J. (2000). Factors affecting the sequestration of aflatoxins by Lactobacillus

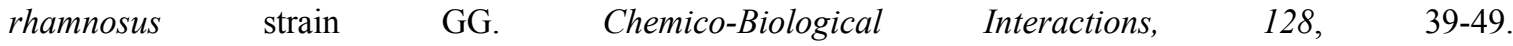
http://dx.doi.org/10.1016/S0009-2797(00)00186-1

Hathout, A. S., Mohameda, S. R., El-Nekeety, A. A., Hassan, N. S., Aly, S. E., \& Abdel-Wahhab, M. A. (2011). Ability of Lactobacillus casei and Lactobacillus reuteri to protect against oxidative stress in rats fed aflatoxins-contaminated diet. Toxicon, 58, 179-186. http://dx.doi.org/10.1016/j.toxicon.2011.05.015

Hernandez-Mendoza, A., Garcia, H. S., \& Steele, J. L. (2009). Screening of Lactobacillus casei strains for their ability to bind aflatoxin B1. Food and Chemical Toxicology, 47, 1064-1068. http://dx.doi.org/10.1016/j.fct.2009.01.042

James, B. (2005). Public awareness of aflatoxin and food quality xontrol in Benin. International Institute of Tropical Agriculture.

Joseph, P. J., Dave, R. I., \& Shah, N. P. (1998). Antagonism between yogurt bacteria and probiotic bacteria isolated from commercial starter cultures, commercial yogurts, and a probiotic capsule. Food Australia, 50, 20-3.

Kailasapathy, K. (2006). Survival of free and encapsulated probiotic bacteria and their effect on the sensory properties of yoghurt. LWT - Food Science and Technology, 39, 1221-1227. http://dx.doi.org/10.1016/j.lwt.2005.07.013

Kang, D. W., Park, J. G., Ilhan, Z. E., Wallstrom, G., Labaer, J., Adams, J. B., \& Krajmalnik-Brown, R. (2013). Reduced incidence of Prevotella and other fermenters in intestinal microflora of autistic children. PLoS One, 8(7), e68322. http://dx.doi.org/10.1371/journal.pone.0068322

Kataria, J., Li, N., Wynn, J. L., \& Neu, J. (2009). Probiotic microbes: do they need to be alive to be beneficial? Nutrition Reviews, 67, 546-550. http://dx.doi.org/10.1111/j.1753-4887.2009.00226.x

Kayser, F. H. (2003). Safety aspects of enterococci from the medical point of view. International Journal of Food Microbiology, 88, 255-262. http://dx.doi.org/10.1016/S0168-1605(03)00188-0

Kumar, M., Verma, V., Nagpal, R., Kumar, A., Gautam, S. K., Behare, P. V., ... Aggarwal, P. K. (2011). Effect of probiotic fermented milk and chlorophyllin on gene expressions and genotoxicity during AFB1-induced hepatocellular carcinoma. Gene, 490, 54-59. http://dx.doi.org/10.1016/j.gene.2011.09.003

Kumar, M., Verma, V., Nagpal, R., Kumar, A., Behare, P. V., Singh, B., \& Aggarwal, P. K. (2012). Anticarcinogenic effect of probiotic fermented milk and chlorophyllin on aflatoxin-B1-induced liver carcinogenesis in rats. British Journal of Nutrition, 107, 1006-1016. http://dx.doi.org/10.1017/S0007114511003953

Ma, Q. G., Gao, X., Zhou, T., Zhao, L. H., Fan, Y., Li, X. Y., ... Zhang, J. Y. (2012). Protective effect of Bacillus subtilis ANSB060 on egg quality, biochemical and histopathological changes in layers exposed to aflatoxin B1. Poultry Science, 91, 2852-7. http://dx.doi.org/10.3382/ps.2012-02474

Madrigal-Santillán, E., Madrigal-Bujaidar, E., Márquez-Márquez, R., \& Reyes, A. (2006). Antigenotoxic effect of Saccharomyces cerevisiae on the damage produced in mice fed with aflatoxin B1 contaminated corn. Food and Chemical Toxicology, 44, 2058-2063. http://dx.doi.org/10.1016/j.fct.2006.07.006

Mallebrera, B., Meca, G., Manyes, L., Mañes, J., \& Font, G. (2013). Influence of pro- and prebiotics on gastric, duodenal and colonic bioaccessibility of the mycotoxin beauvericin. Journal of Food Composition and Analysis, 32, 141-149. http://dx.doi.org/10.1016/j.jfca.2013.09.003

Martin, R., Miquel, S., Langella, P., \& Bermúdez-Humarán, L. G. (2014). The role of metagenomics in understanding the human microbiome in health and disease. Virulence, 5, Epub ahead of print. http://dx.doi.org/10.4161/viru.27864

Mateo, E. M., Medina, A., Mateo, R., \& Jiménez, M. (2010). Effect of ethanol on the ability of Oenococcus oeni to remove ochratoxin A in synthetic wine-like media. Food Control, 21, 935-941. http://dx.doi.org/10.1016/j.foodcont.2009.03.012

Mechoud, M. A., Juarez, G. E., Font de Valdez, G., \& Rodriguez, A. V. (2012). Lactobacillus reuteri CRL 1098 and Lactobacillus acidophilus CRL 1014 differently reduce in vitro immunotoxic effect induced by Ochratoxin A. Food and Chemical Toxicology, 50, 4310-4315. http://dx.doi.org/10.1016/j.fct.2012.07.070 
Mitra, S., Förster-Fromme, K., Damms-Machado, A., Scheurenbrand, T., Biskup, S., Huson, D. H., \& Bischoff, S.C. (2013). Analysis of the intestinal microbiota using SOLiD 16S rRNA gene sequencing and SOLiD shotgun sequencing. BMC Genomics, 14, S5-S16. http://dx.doi.org/10.1186/1471-2164-14-S5-S16

Moreau, M. C., \& Gaboriau-Routhiau, V. (2000). Influence of resident intestinal microflora on the development and functions of the intestinal-associated lymphoid tissue. In R. Fuller \& G. Perdigón (Eds.), Probiotics 3 Immunomodulation by the gut flora and probiotics (pp. 69-114). Dordrecht, Holland: Kluwer Academic Publishers.

Mykkänen, H., Gratz, S., \& El-Nezami, H. (2011). Applied studies with probiotics: fundamentals for meeting the health claims. In W. Kneife \& S. Salminen (Eds.), Probiotics and Health Claims. Oxford, UK: Wiley-Blackwell.

Neha, A., Kamaljit, S., Ajay, B., \& Tarun, G. (2012). Probiotic: as effective treatment of diseases. International Research Journal of Pharmacy, 3, 96-101.

Oelschlaeger, T. A. (2010). Mechanisms of probiotic actions-a review. International Journal of Medical Microbiology, 300, 57-62. http://dx.doi.org/10.1016/j.jimm.2009.08.005

Ouwehand, A. C., \& Salminen, S. J. (1998). The health effects of cultured milk products with viable and $\begin{array}{llllll}\text { non-viable bacteria. } & \text { International Dairy }\end{array}$ http://dx.doi.org/10.1016/S0958-6946(98)00114-9

Peltonen, K., El-Nezami, H., Haskard, C., Ahokas, J., \& Salminen, S. (2001). Aflatoxin B1 binding by dairy strains of lactic acid bacteria and bifidobacteria. Journal of Dairy Science, 84, 2152-2156. http://dx.doi.org/10.3168/jds.S0022-0302(01)74660-7

Pizzolitto, R. P., Salvano, M. A., \& Dalcero, A. M. (2012). Analysis of fumonisin B1 removal by microorganisms in co-occurrence with aflatoxins B1 and the nature of the binding process. International Journal of Food Microbiology, 156, 214-221. http://dx.doi.org/10.1016/j.ijfoodmicro.2012.03.024

Pizzolitto, R. P., Armando, M. R., Salvano, M. A., Dalcero, A. M., \& Rosa, C. A. (2013). Evaluation of Saccharomyces cerevisiae as an antiaflatoxicogenic agent in broiler feedstuffs. Poultry Science, 92, 1655-63. http://dx.doi.org/10.3382/ps.2012-02846

Qian, G. S., Ross, R. K., Yu, M. C., Yuan, J. M., Gao, Y. T., Henderson, B. E., ... Groopman, J. D. (1994). A follow-up study of urinary markers of aflatoxin exposure and liver cancer risk in Shanghai, People's Republic of China. Cancer Epidemiology, Biomarkers \& Prevention, 3, 3-10.

Rinkinen, M., Jalava, K., Westermarck, E., Salminen, S., \& Ouwehand, A. C. (2003). Interaction between probiotic lactic acid bacteria and canine enteric pathogens: a risk factor for intestinal Enterococcus faecium colonization? Veterinary Microbiology, 92, 111-119. http://dx.doi.org/10.1016/S0378-1135(02)00356-5

Sanders, M. E., Lenoir-Wijnkoop, I., Salminen, S., Merenstein, D. J., Gibson, G. R., Petschow, B. W., ... Pot, B. (2014). Probiotics and prebiotics: prospects for public health and nutritional recommendations. Annals of the New York Academy of Sciences, 1309, 19-29. http://dx.doi.org/10.1111/nyas.12377

Sekirov, I., Russell, S. L., Antunes, L. C. M., \& Finlay, B. (2010). Gut microbiota in health and disease. Physiology Reviews, 90, 859-904. http://dx.doi.org/10.1152/physrev.00045.2009

Serrano-Niño, J. C., Cavazos-Garduño, A., Hernandez-Mendoza, A., Applegate, B., Ferruzzi, M. G., San Martin-González, M. F., \& García, H. S. (2013). Assessment of probiotic strains ability to reduce the bioaccessibility of aflatoxins M1 in artificially contaminated milk using an in vitro digestive model. Food Control, 31, 202-207. http://dx.doi.org/10.1016/j.foodcont.2012.09.023

Slizewska, K., Nowak, A., Libudzisz, Z., \& Blasiak, J. (2010). Probiotic preparation reduces the faecal water genotoxicity in chickens fed with aflatoxin B1 contaminated fodder. Research in Veterinary Science, 89, 391-395. http://dx.doi.org/10.1016/j.rvsc.2010.04.004

Soccol, C. R., Vandenberghe, L. P. S., Spier, M. R., Medeiros, A. B. P., Yamaguishi, C. T., Lindner, J. D., ... Thomaz-Soccol, V. (2010). The potential of probiotics: a review. Food Technology \& Biotechnology, 48, 413-434.

Stanton, C., Desmond, C., Coakley, M., Collins, J. K., Fitzgerald, G., \& Ross, R. P. (2003). Challenges facing development of probiotic-containing functional foods. In E. R. Farnworth (Ed.), Handbook of fermented functional foods (pp. 27-58). Boca Raton, USA: CRC Press. http://dx.doi.org/10.1201/9780203009727.ch2

Tan, Q., Xu, H., Aguilar, Z.P., Peng, S., Dong, S., Wang, B., .. Wei, H. (2013). Safety assessment and probiotic 
evaluation of Enterococcus faecium YF5 isolated from sourdough. Journal of Food Science, 78, M587-93. http://dx.doi.org/10.1111/1750-3841.12079

Tannock, G. W. (2003). The intestinal microflora. In R. Fuller \& G. Perdigón (Eds.), Gut flora, nutrition, immunity and health (pp. 1-23). Oxford, UK: Balckwell Publishing.

Topcu, A., Bulat, T., Wishah, R., \& Boyac, I. H. (2010). Detoxification of aflatoxin B1 and patulin by Enterococcus faecium strains. International Journal of Food Microbiology, 139, 202-205. http://dx.doi.org/10.1016/j.ijfoodmicro.2010.03.006

Turner, P. C., Wub, Q. K., Piekkola, S., Gratz, S., Mykkanen, H., \& El-Nezami, H. (2008). Lactobacillus rhamnosus strain GG restores alkaline phosphatase activity in differentiating Caco-2 cells dosed with the potent mycotoxin deoxynivalenol. Food and Chemical Toxicology, 46, 2118-2123. http://dx.doi.org/10.1016/j.fct.2008.02.004

Vinderola, C. G., Bailo, N., \& Reinheimer, J. A. (2000). Survival of probiotic microflora in Argentinian yoghurts during refrigerated storage. Food Research International, 33, 97-102. http://dx.doi.org/10.1016/S0963-9969(00)00011-9

Vinderola, C. G., Mocchiutti, P., \& Reinheimer, J. A. (2002). Interactions among lactic acid starter and probiotic bacteria used for fermented dairy products. Journal of Dairy Science, 85, 721-729. http://dx.doi.org/10.3168/jds.S0022-0302(02)74129-5

Vinderola, C. G., Medici, M., \& Perdigón, G. (2004). Relationship between interaction sites in the gut, hydrophobicity, mucosal immunomodulating capacities and cell wall protein profiles in indigenous and

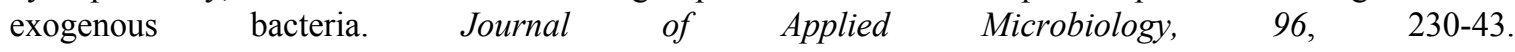
http://dx.doi.org/10.1046/j.1365-2672.2004.02158.x

Zain, M. E. (2011). Impact of mycotoxins on humans and animals. Journal of Saudi Chemical Society, 15, 129-144. http://dx.doi.org/10.1016/j.jscs.2010.06.006

\section{Copyrights}

Copyright for this article is retained by the author(s), with first publication rights granted to the journal.

This is an open-access article distributed under the terms and conditions of the Creative Commons Attribution license (http://creativecommons.org/licenses/by/3.0/). 